\title{
Selective Hydrogenation of Levulinic Acid Using Ru/C Catalysts Prepared by Sol-Immobilisation
}

\author{
Daniel R. Jones ${ }^{1} \cdot$ Sarwat Iqbal $^{1}$ • Peter J. Miedziak ${ }^{1}$ - David J. Morgan ${ }^{1}$ • Jennifer K. Edwards ${ }^{1} \cdot$ Qian He $^{1}$. \\ Graham J. Hutchings ${ }^{1}$
}

Published online: 23 April 2018

(c) The Author(s) 2018

\begin{abstract}
A $1 \% \mathrm{Ru} / \mathrm{C}$ catalyst prepared by the sol immobilization method showed a high yield of $\gamma$-valerolactone from levulinic acid. We performed an optimization of the catalyst by varying the preparation variables involved in the sol immobilization method and detremined that the ratio of PVA, $\mathrm{NaBH}_{4}$ to $\mathrm{Ru}$ and heat treatment conditions play a crucial role in the synthesis of active and selective catalysts. By varying these parameters we have identified the optimum conditions for catalyst preparation by providing well dispersed nanoparticles of $\mathrm{RuO}_{\mathrm{x}}$ on the carbon support that are reducible under low reaction temperature and in turn gave an enhanced catalytic activity. In contrast to a catalyst prepared without using a PVA stabiliser, the use of a small amount PVA $(\mathrm{PVA} / \mathrm{Ru}=0.1)$ provided active nanoparticles, by controlling the steric size of the Ru nanoparticles. An optimum amount of $\mathrm{NaBH}_{4}$ was required in order to provide the reducible $\mathrm{Ru}$ species on the surface of catalyst and further increase in $\mathrm{NaBH}_{4}$ was found to cause a decline in activity that was related to the kinetics of nanoparticle formation during catalyst preparation. A variation of heat treatment temperature showed a corresponding decrease in catalytic activity linked with the sintering and an increase in particle size.
\end{abstract}

\section{Graphical Abstract}

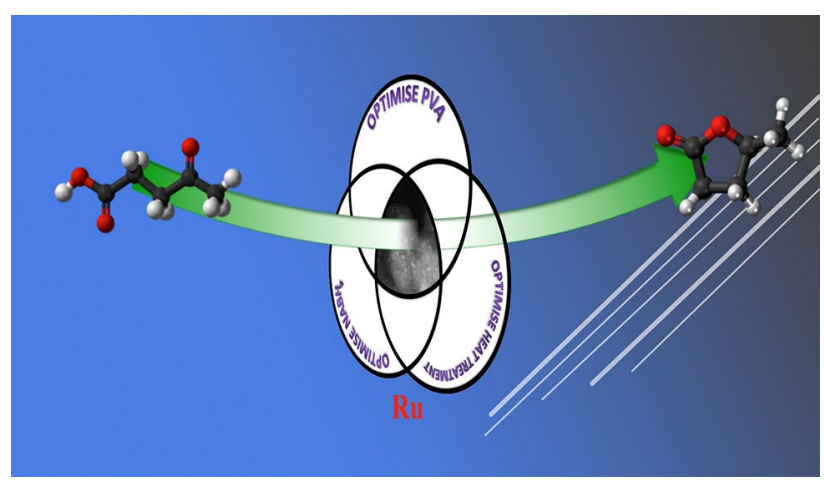

Keywords Levulinic acid $\cdot$ Ruthenium $\cdot$ Catalyst $\cdot$ Hydrogenation

Electronic supplementary material The online version of this article (https://doi.org/10.1007/s11244-018-0927-0) contains supplementary material, which is available to authorized users.

Graham J. Hutchings

hutch@cardiff.ac.uk

1 Cardiff Catalysis Institute, Main Building, Park Place, Cardiff CF10 3AT, UK

\section{Introduction}

Biomass is considered a promising alternative to nonrenewable resources for the production of biofuels in the future. An extensive amount of work has been published on identification and study of the chemical transformations of biomass into platform chemicals and fuel derivatives [1,2]. One of the most adopted approaches among these studies 
is the conversion of levulinic acid (LA) into various petroleum derivatives due to it being listed amongst the ten most important target chemicals by the US-DOE biomass program [3]. LA is commonly prepared by biomass conversion and furfural hydrolysis methods $[4,5]$.

Recently a number of valuable LA derivatives have been reported; i.e. levulinate esters and $\gamma$-valerolactone $(\mathrm{gVL})$ [6-9]. gVL has a number of applications because of its low toxicity and is considered as a sustainable liquid for transportation applications [10]. It can be converted into butene and $\mathrm{CO}_{2}$, followed by polymerization in order to produce a qualified aircraft fuel [11]. gVL is often produced by the hydrogenation of LA with a noble metal catalyst. Schuette et al. [12] were the first to study the hydrogenation of LA for the synthesis of gVL in organic solvents using a Ptbased catalyst, an $87 \%$ yield of gVL was reported after $44 \mathrm{~h}$ reaction under 3 bar of pure hydrogen. Christian et al. [13]. reported $94 \% \mathrm{gVL}$ yield with Raney nickel and copper chromite catalysts under 202 barg pure hydrogen at $250{ }^{\circ} \mathrm{C}$. Pd, $\mathrm{Ni}$ and Pt based catalysts were reported by Mehdi et al. [14] for LA hydrogenation into gVL through dehydration and hydrogenation steps. A process for the production of $\mathrm{gVL}$ in supercritical $\mathrm{CO}_{2}$ was patented with a noble metal based catalyst by Manzer et al. [15]. Poliakoff and co-workers [16] showed that supercritical $\mathrm{CO}_{2}$ can fully convert LA in to $\mathrm{gVL}$ in the presence of $5 \% \mathrm{Ru} / \mathrm{SiO}_{2}$ catalyst at $100 \mathrm{barg}$ pressure of pure hydrogen. Colloidal Ru nanoparticles alone are able to catalyse the transformation, either using an external hydrogen source or formic acid (transfer hydrogenation) [17], but owing to the difficulty in separating and reusing colloids, generally heterogeneous systems are used. Up to 90\% conversion, with complete selectivity to $\mathrm{gVL}$ has been achieved in water at $130{ }^{\circ} \mathrm{C}$ and 12 bar $\mathrm{H}_{2}$ using Ru colloids [18]. Addition of solid acids to the reaction has also been shown to increase activity, leading to similar conversion but with milder reaction conditions. A system comprising a $5 \mathrm{wt} \% \mathrm{Ru} / \mathrm{C}$ catalyst and Amberlyst 70 achieved $98 \% \mathrm{gVL}$ yield at $70{ }^{\circ} \mathrm{C}$ and 5 bar $\mathrm{H}_{2}$ after $3 \mathrm{~h}$ reaction [19]. Piskun et al. carried out a study using pelleted catalysts in much the same way industry prefers to use in order to avoid excessive pressure drop in a continuous flow system [20]. Due to the size of catalyst particles, they found that the activity was strongly affected by mass transport effects, but they obtained quite acceptable yields of GVL of $95 \%$. There was a loss in catalytic activity after longer reaction times, attributed to a loss of surface area due to coking and Ru particle sintering; in this case Ru leaching was reported to be minimal.

Weckhuysen and co-workers showed that the addition of $\mathrm{Pd}$ to $\mathrm{Ru}$ catalysts diluted and isolated the active sites, resulting in an excellent selectivity to gVL and an enhanced stability on catalyst reuse due to the prevention of sintering [21]. These effects, however, were also achieved with another bimetallic $\mathrm{Ru} / \mathrm{Sn} / \mathrm{C}$ catalyst reported by Wettstein et al. [22] which has the advantage of being cheaper to produce due to the use of Sn over Pd. A recent study that has emerged from the group of Ren and co-workers has revealed a unique and novel catalyst synthesis of high surface area Ru nanoparticles supported on carbon nanofibers $\left(>1000 \mathrm{~m}^{2} \mathrm{~g}^{-1}\right)$, that are 18 times more active (in terms of turnover frequency) than the leading commercial Ru catalyst for LA hydrogenation, suggesting that the need for new novel syntheses has been recognised [23]. It is clear from the earlier studies that the precious metal catalysts were gradually being employed for gVL synthesis from LA because of their superior catalytic activity; Ru being one of the most extensively studied catalyst systems for this reaction [18, 24-27]. While optimisation of the reaction conditions has been studied for commercially available $\mathrm{Ru} / \mathrm{C}$ catalysts $[19,20,28,29]$ the optimisation of the catalyst preparation method and the design of catalysts has not yet been well studied. In this paper, we have studied $1 \% \mathrm{Ru} / \mathrm{C}$ catalysts prepared by the sol immobilization method and a variation of catalyst preparation variables was has been investigated.

\section{Experimental}

\subsection{Catalyst Preparation}

$1 \mathrm{wt} \% \mathrm{Ru} / \mathrm{C}$ catalysts were prepared by sol immobilization (SI). In a typical synthesis a solution of poly vinyl alcohol (Sigma-Aldrich) and $\mathrm{RuCl}_{3} \times \mathrm{xH}_{2} \mathrm{O}$ (Sigma-Aldrich) was mixed in water $(800 \mathrm{ml}) . \mathrm{NaBH}_{4}$ (Sigma-Aldrich) was added to generate the sol. After 30 min the carbon (Vulcan XC72R) was added and the solution was acidified to $\mathrm{pH} 2$ with sulphuric acid. The catalysts were then filtered and dried overnight $(16 \mathrm{~h})$ at $110{ }^{\circ} \mathrm{C}$. To study the effect of heat treatment, one batch of catalyst was divided into four portions which were heated in flowing $\mathrm{N}_{2}$ separately at $300,400,500$, and $600{ }^{\circ} \mathrm{C}$ at a ramp rate of $10^{\circ} \mathrm{C} \mathrm{min}^{-1}$ for $3 \mathrm{~h}$.

\subsection{Levulinic Acid Hydrogenation}

In a typical experiment the desired amount of the catalyst was added to the LA solution $\left(10 \mathrm{ml}, 5 \mathrm{wt} \% \mathrm{LA} / \mathrm{H}_{2} \mathrm{O}\right)$ in a Parr autoclave (50 ml, equipped with a Teflon liner) which was purged with nitrogen and then with hydrogen. It was then heated to the desired temperature, pressurized with $\mathrm{H}_{2}$ (35 barg) and stirred at $1000 \mathrm{rpm}$. After the desired reaction time the autoclave was placed in an ice bath. When the temperature reached at $10^{\circ} \mathrm{C}$ the gases were vented and the autoclave was opened. The liquid was filtered and analysed.

Liquid products were analysed using a GC equipped with CP-Sil 5CB (50 m, $0.32 \mathrm{~mm}, 5 \mu \mathrm{m})$ column and FID detector. Acetonitrile was used as a standard. Gases were vented into a gas bag and analysed with a GC equipped with TCD 
and FID detectors and with a methaniser column. Products in the gas phase usually accounted for less than $0.1 \%$.

For reusability studies an excess of catalyst was subjected to a reaction as described in above section. After the completion of reaction, the catalyst was filtered, washed (both with water and acetone) and dried in an oven at $110{ }^{\circ} \mathrm{C}$ for $16 \mathrm{~h}$ (1 use). From this batch of catalyst, the requisite amount for a regular reaction was taken in order to determine its activity. The used batch was subjected to another reaction, dried and filtered as before, and the requisite amount for a regular reaction taken in order to determine its activity (two uses). This procedure was repeated to determine the activity of the catalyst for the desired number of uses.

\subsection{Catalyst Characterization}

$X$-ray diffraction $(\mathrm{XRD})$ was performed using a PANalytical X'Pert Pro fitted with an X'Celerator detector and a $\mathrm{Cu} \mathrm{K \alpha}$ $\mathrm{X}$-ray source operated at $40 \mathrm{kV}$ and $40 \mathrm{~mA}, 2 \theta=10^{\circ}-80^{\circ}$. Each sample was scanned from $2 \theta=10^{\circ}-80^{\circ}$ for $30 \mathrm{~min}$. The catalysts were ground into fine powder before the analysis. The results obtained were compared with the information in SPDF library for each catalyst. Temperature programmed reduction (TPR) was carried out using a Thermo 1100 series TPDRO under $75 \mathrm{ml} \mathrm{min}{ }^{-1} 5 \% \mathrm{H}_{2} / \mathrm{Ar}, 10{ }^{\circ} \mathrm{C} \mathrm{min}^{-1} \mathrm{ramp}$ rate. Samples $(0.1 \mathrm{~g})$ were pre-treated at $110^{\circ} \mathrm{C}$ (heating rate $=20^{\circ} \mathrm{C} \mathrm{min}^{-1}$ ) under Ar for $1 \mathrm{~h}$ prior to reduction in order to clean the surface. Analysis was performed under $10 \% \mathrm{H}_{2} / \mathrm{Ar}$ (BOC $99.99 \%, 25 \mathrm{ml} \mathrm{min}^{-1}$ ) 30-800 ${ }^{\circ} \mathrm{C}$, $20{ }^{\circ} \mathrm{C} \mathrm{min}{ }^{-1}$. X-ray photoelectron spectroscopy (XPS) was performed using a Kratos Axis Ultra-DLD photoelectron spectrometer, using monochromatic $\mathrm{Al} k \alpha$ radiation, operating at $144 \mathrm{~W}$ power. High resolution and survey scans were performed at pass energies of 40 and $160 \mathrm{eV}$ respectively. Spectra were calibrated to the C (1s) signal at $284.5 \mathrm{eV}$, and quantified using CasaXPS v2.3.17, using modified Wagner sensitivity factors as supplied by the instrument manufacturer. Due to the complication of the overlap of ruthenium with the carbon region, data analysis was performed using $\mathrm{Ru}$ line shapes derived from fits obtained from pure standard compounds [30]. Further details on this method have been detailed by Baltrusaitis et al. [31]. Surface area was determined by multi-point $\mathrm{N}_{2}$ adsorption at $-196{ }^{\circ} \mathrm{C}$ on a Micromeretics Gemini 2360 according to the Brauner-Emmet-Teller (BET) method. Prior to the analysis, samples were degassed at $120{ }^{\circ} \mathrm{C}$ for $1 \mathrm{~h}$ under $\mathrm{N}_{2}$ flow. Transmission electron microscopy (TEM). TEM was carried out using a Jeol 2100 with a $\mathrm{LaB}_{6}$ filament operating at $200 \mathrm{kV}$. Samples were prepared by dispersing the powder catalyst in ethanol and dropping the suspension onto a lacey carbon film over a 300 mesh copper grid. Microwave plasma atomic emission spectroscopy (MP-AES). MP-AES analysis was performed using an Agilent 4100 MP-AES machine.
The samples were introduced to the nitrogen plasma using a single pass spray chamber at a pressure of $120 \mathrm{kPa}$ without air injection. The instrument was calibrated with 1, 2, 4, $7,10 \mathrm{ppm}$ standard solutions in $10 \% \mathrm{HCl}$. A levulinic acid rinse solution (5\%) was introduced between samples for $15 \mathrm{~s}$ to ensure there was no sample contamination. Ru content was analysed using two emission lines with wavelengths of 349.894 and $371.803 \mathrm{~nm}$.

\section{Results and Discussion}

\subsection{Variation of PVA/Ru Ratio}

A range of catalysts were prepared using the sol immobilisation method by varying the ratio of the stabilizer agent (PVA) to the Ru. The catalysts were then used for LA hydrogenation and the results are shown in Fig. 1. It is clear that increasing the PVA content in the catalyst resulted in a gradual decrease in gVL yield. While it is known that the use of sufficient PVA can result in nanoparticles with a uniform distribution of small particles, overuse of PVA can result in blocking of the active sites and we consider this to be the case when a PVA/Ru ratio of 3 was used. This effect is similar to that previously reported for lactic acid hydrogenation [32]. It is important to note that the use of small amounts of PVA (i.e. $\mathrm{PVA} / \mathrm{Ru}=0.1$ ) was required to obtain a reasonably high catalytic activity. A catalyst prepared without PVA gave an average $\mathrm{gVL}$ yield of $50 \%$.

The BET surface area for the catalysts prepared by variation of the PVA/Ru ratio is shown in the Supplementary Information Table S1. The surface area of the untreated carbon is $220 \mathrm{~m}^{2} \mathrm{~g}^{-1}$. When a low PVA content was used $(0.1$ and 0.25), the BET surface area was higher than that of the support at 250 and $240 \mathrm{~m}^{2} \mathrm{~g}^{-1}$ respectively. As the PVA/ $\mathrm{Ru}$ ratio was increased above 0.25 , a trend of decrease in

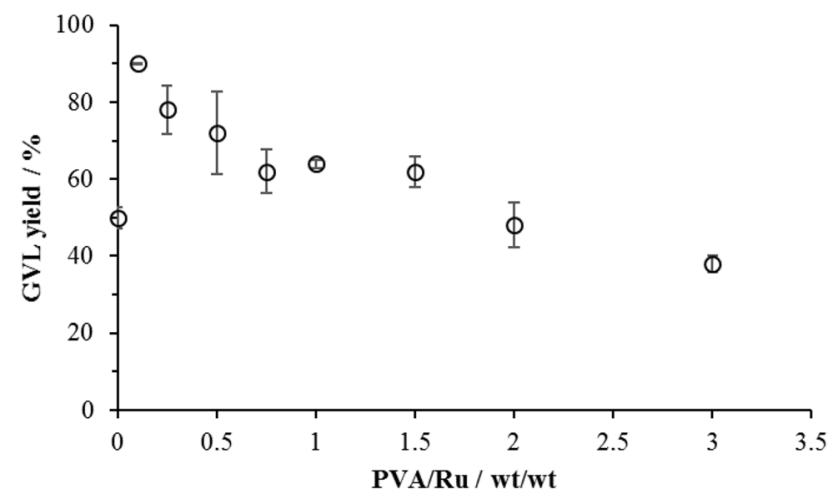

Fig. $1 \mathrm{gVL}$ yield data for $1 \% \mathrm{Ru} / \mathrm{C}$ catalysts prepared by the variation of PVA/Ru ratio. Reaction conditions $100{ }^{\circ} \mathrm{C}, \mathrm{H}_{2} 5 \mathrm{barg}, 1 \mathrm{~h}$, substrate $5 \mathrm{wt} \% \mathrm{LA} / \mathrm{H}_{2} \mathrm{O}$, catalyst $(0.015 \mathrm{~g})$ 
surface area was observed, the surface area remained fairly consistent from 0.5 to 3.0 PVA/Ru ratio. It appears that when high concentrations of PVA was used, it can build up on the surface and cause a decrease in the surface area. However, it is not possible to relate the catalytic activity with total surface area.

TPR analysis of a selection of the catalysts prepared with varying amounts of PVA are presented in Fig. 2. Catalysts prepared with PVA/Ru ratio of between 0.1 and 0.5 showed three reduction signals. The signals observed at the lower temperature are reported to be due to the reduction of $\mathrm{RuO}_{\mathrm{x}}$ species to $\mathrm{Ru}^{0}$, or the reduction of $\mathrm{Ru}(\mathrm{IV}) / \mathrm{Ru}(\mathrm{III})$ to $\mathrm{Ru}(\mathrm{II})$, and the signals between 200 and $400{ }^{\circ} \mathrm{C}$ are due to a reduction of $\mathrm{Ru}(\mathrm{II})$ to $\mathrm{Ru}^{0}[33,34]$. Reduction signals at higher temperature (above $500{ }^{\circ} \mathrm{C}$ ) were due to reduction of species attached to the carbon supports, or methanation of the carbon support, as shown by mass spectrometry of a typical $1 \% \mathrm{Ru} / \mathrm{C}$ catalyst carried out during the TPR experiments (Fig. S1), where an evolution of methane and carbon monoxide was observed with an increase in the reduction temperature. Interestingly, water removal at higher temperature was also observed suggesting support degradation and removal of oxygen containing species at high temperature

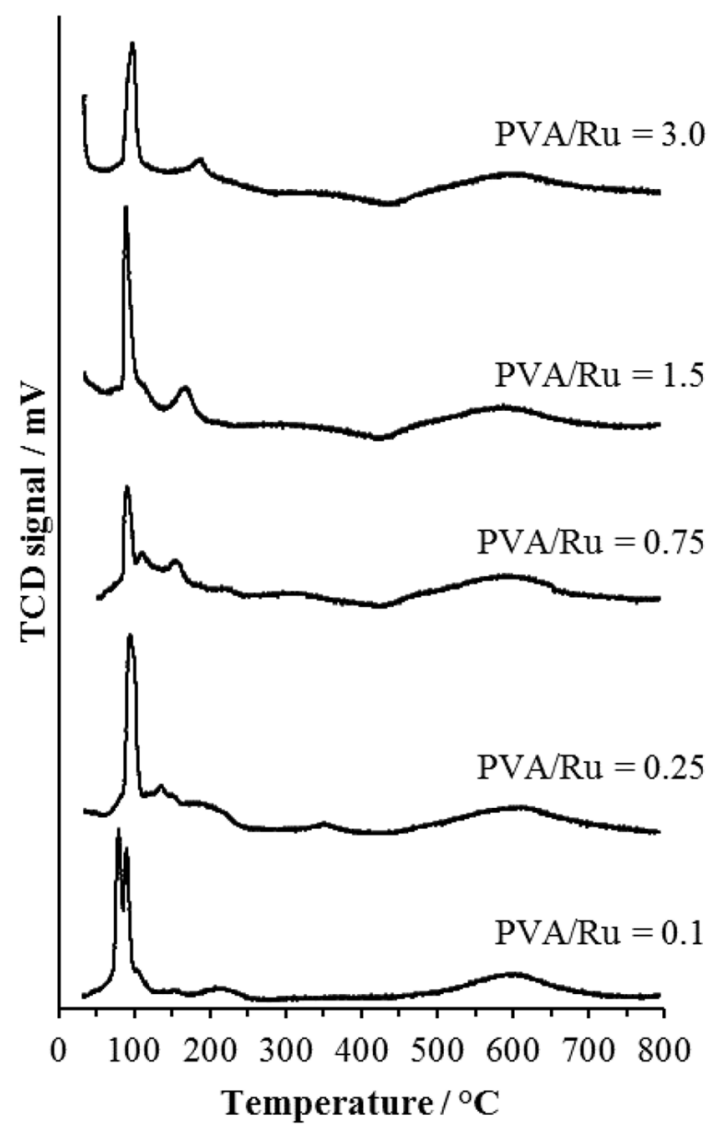

Fig. 2 TPR profiles of $1 \% \mathrm{Ru} / \mathrm{C}$ catalysts prepared with variation of PVA/Ru ratio (the pre-treatment step had already removed the adsorbed water in catalyst).

Catalysts prepared with a PVA/Ru ratio of 0.1 showed much sharper reduction signals below $100{ }^{\circ} \mathrm{C}$ and considerably less signal in the region of $150-200{ }^{\circ} \mathrm{C}$, which implies that this catalyst was more easily reducible compared with the catalysts prepared with a higher ratios of PVA/Ru $>0.1$. The generally superior activity of these catalysts for LA hydrogenation (Fig. 1) suggests that reducibility of the catalyst is an important factor in determining the catalytic activity. The catalysts prepared with PVA/Ru $>0.1$ showed reduction signals at or higher than $100{ }^{\circ} \mathrm{C}$ had much lower catalytic activity (Fig. 1). These results imply that reduced forms of $\mathrm{Ru}$ are important for these reactions to proceed. Further to this, it is possible that the PVA used during the catalyst preparation was removed at higher temperatures and contributed to the reduction signal above $450{ }^{\circ} \mathrm{C}$, but quantifying the loss of PVA from a carbon support is incredibly difficult.

All of the catalysts prepared by the variation of the PVA/ $\mathrm{Ru}$ ratio were analysed by powder XRD and the results are presented in the Supplementary information Fig. S2. All the catalysts showed typical pattern of pure carbon and no reflections related with $\mathrm{Ru}$ oxide or metallic $\mathrm{Ru}$ were detectable. It would imply that Ru was well dispersed on carbon and may have a particle size less than $5 \mathrm{~nm}$. XPS was performed on the catalysts prepared with varying ratio of PVA to Ru and the data are presented in Table 1. Fitting of the spectra using experimentally derived line shape models acquired under identical conditions, reveal Ru3d( $5 / 2$ ) binding energies of $281.3 \mathrm{eV}( \pm 0.2 \mathrm{eV})$, consistent with hydrated $\mathrm{RuO}_{2}$ for all the catalysts [30]. The small changes in binding energies with the different PVA/Ru ratios are within experimental confidence limits.

\subsection{Variation of $\mathrm{NaBH}_{4} / \mathrm{Ru}$ ratio}

With the knowledge that a PVA/Ru ratio of 0.1 provided the most active catalyst, $1 \% \mathrm{Ru} / \mathrm{C}$ catalysts were prepared with varying amounts of $\mathrm{NaBH}_{4}$ and were tested for LA hydrogenation in order to investigate the effect of a varying the degree of metal reduction during the preparation stage. The activity data for LA conversion is shown in Fig. 3. Aside from the observation that a $\mathrm{NaBH}_{4} / \mathrm{RuCl}_{3}$ ratio of 2.5 was

Table 1 XPS analysis of a selection of catalysts with different PVA/ $\mathrm{Ru}$ ratios

\begin{tabular}{lll}
\hline PVA/Ru/wt/wt & $\mathrm{Ru}\left(3 \mathrm{~d}_{5 / 2}\right) / \mathrm{eV}$ & $\mathrm{Ru}$ species \\
\hline 0.1 & 281.5 & $\mathrm{RuO}_{2} \cdot\left(\mathrm{xH}_{2} \mathrm{O}\right)$ \\
1.0 & 281.3 & $\mathrm{RuO}_{2} \cdot\left(\mathrm{xH}_{2} \mathrm{O}\right)$ \\
3.0 & 281.2 & $\mathrm{RuO}_{2} \cdot\left(\mathrm{xH}_{2} \mathrm{O}\right)$ \\
\hline
\end{tabular}




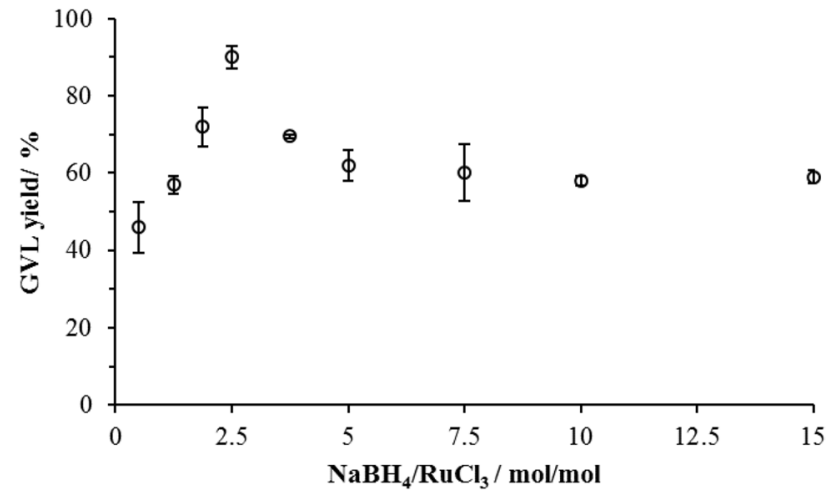

Fig. $3 \mathrm{gVL}$ yield for the catalysts prepared by variation of $\mathrm{NaBH}_{4} / \mathrm{Ru}$ ratio (mol/mol). Reaction conditions $100{ }^{\circ} \mathrm{C}, \mathrm{H}_{2} 5 \mathrm{barg}, 1 \mathrm{~h}$, Substrate $5 \mathrm{wt} \% \mathrm{LA} / \mathrm{H}_{2} \mathrm{O}$, catalyst $(0.015 \mathrm{~g})$

found to be optimal, a decrease and a consistent activity was observed with an increased ratio of $\mathrm{NaBH}_{4} / \mathrm{RuCl}_{3}>2.5$. An incomplete reduction of the Ru during the preparation of the sol would be expected when an amount of $\mathrm{NaBH}_{4}$ lower than the stoichiometric value required for the reduction of $\mathrm{Ru}$ is used. As the amount of $\mathrm{NaBH}_{4}$ used increases, there would be more reduced $\mathrm{Ru}$ prepared in sol and later supported on the carbon. The increase in activity up to $\mathrm{NaBH}_{4} / \mathrm{RuCl}_{3} \leq 2.5$ can be attributed to increasingly available metallic Ru during preparation. The decrease and subsequent stabilisation of the activity when $\mathrm{NaBH}_{4} / \mathrm{RuCl}_{3}>2.5$ were used can be related to the kinetics of nanoparticle formation. Turkovic gave an insight into the kinetics of nanoparticle formation using a gold citrate sol and showed that an increased rate of nanoparticles formation generally results in larger nanoparticles [35]. In accordance with this, work by Prati et al. showed that using an excess of $\mathrm{NaBH}_{4}$ in an SI procedure for gold catalysts decreased their activity for glycerol oxidation due to the presence of particles that were too large to achieve high activity [36, 37]. The catalytic data obtained Fig. 4 is in agreement with both of these previous findings. It has been shown in this work and in previous studies [21-23, 32] that small, well dispersed Ru particles are required for high catalytic activity. An increase in $\mathrm{NaBH}_{4} / \mathrm{RuCl}_{3}$ can form large $\mathrm{Ru}$ nanoparticles that are not as active for LA hydrogenation. The consistency of the activity at $\mathrm{NaBH}_{4} / \mathrm{RuCl}_{3}>5$ suggests that an excessive amount of $\mathrm{NaBH}_{4}$ does not increase the rate any further i.e. there comes a point at which the reduction of $\mathrm{RuCl}_{3}$ becomes zero order.

Powder XRD was carried out on this series of catalysts and the results are presented in Supplementary information Fig. S3. Once again, as observed with variation of PVA/Ru, there were no significant features to be observed in the XRD patterns, indicating that small, well dispersed Ru particles were present on the support surface.

The BET surface area (Table 2) was shown to decrease in line with increasing $\mathrm{NaBH}_{4} / \mathrm{RuCl}_{3}$ ratio. Given that when the amount of $\mathrm{NaBH}_{4}$ used was below $\mathrm{NaBH}_{4} / \mathrm{RuCl}_{3}=1$ incomplete reduction of the Ru was observed (due to the stoichiometry of the reduction of $\mathrm{RuCl}_{3}$ ), the kinetics of reduction on the size of Ru nanoparticles based on observations of Turkevic is not necessary [35]. However, it has been noted by Patharkar et al. [38] that unreduced $\mathrm{RuCl}_{3}$ particles can be

Table 2 BET surface areas of $1 \mathrm{wt} \% \mathrm{Ru} / \mathrm{C}$ catalysts prepared with varying $\mathrm{NaBH}_{4} / \mathrm{RuCl}_{3}$ ratios

\begin{tabular}{ll}
\hline $\begin{array}{l}\mathrm{NaBH}_{4} / \mathrm{RuCl}_{3} \\
\text { ratio }\end{array}$ & $\begin{array}{l}\text { BET surface } \\
\text { area } / \mathrm{m}^{2} \mathrm{~g}^{-1}\end{array}$ \\
\hline 0.5 & 250 \\
1.25 & 255 \\
2.5 & 250 \\
5.0 & 230 \\
7.5 & 215 \\
10 & 190 \\
\hline
\end{tabular}

$\mathrm{PVA} / \mathrm{Ru}=0.1$
Fig. 4 Time online data for $1 \%$ $\mathrm{Ru} / \mathrm{C}$ catalysts prepared by variation of $\mathrm{PVA} / \mathrm{NaBH}_{4} / \mathrm{Ru}$ ratios. Rhombus $0.0 / 2.5$, triangle $0.1 / 0.5$, circle $0.1 / 2.5$, square $3.0 / 2.5$, cross $0.1 / 15$. Reaction conditions $100{ }^{\circ} \mathrm{C}, \mathrm{H}_{2} 5 \mathrm{barg}$, $1 \mathrm{~h}$, Substrate $5 \mathrm{wt} \% \mathrm{LA} / \mathrm{H}_{2} \mathrm{O}$, catalyst $(0.015 \mathrm{~g})$

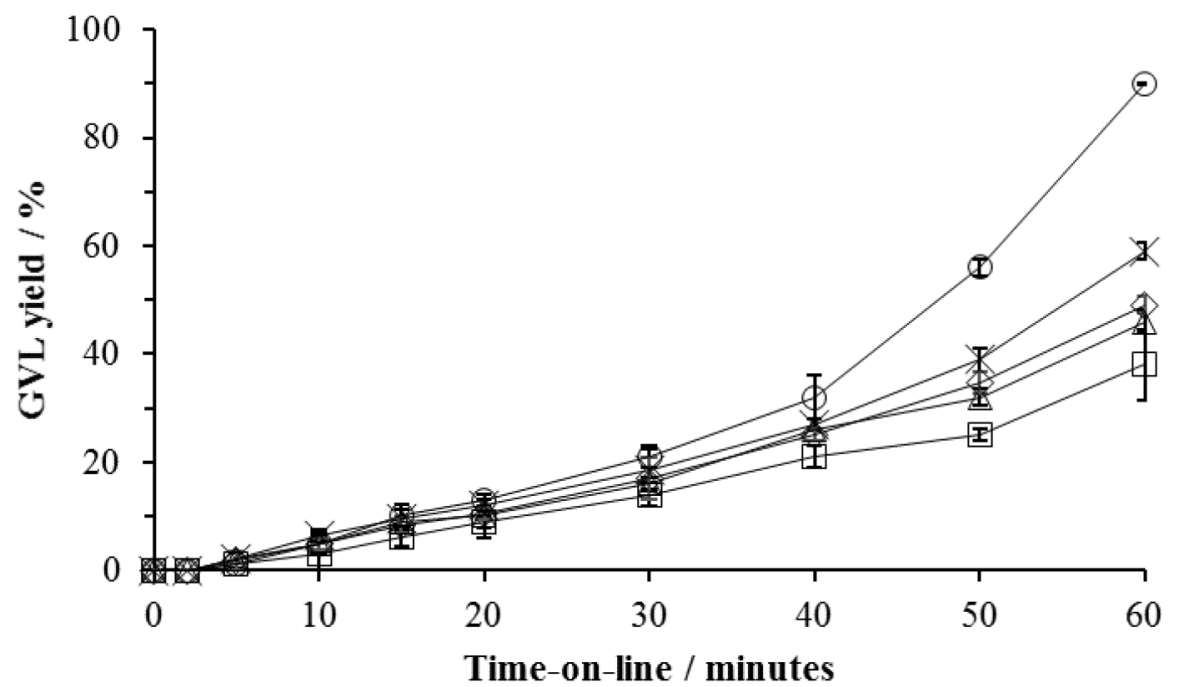


very large, which are known not to be optimal for catalytic activity $[22,23]$. Up to and including $\mathrm{NaBH}_{4} / \mathrm{RuCl}_{3} \leq 2.5$, the activity of the catalysts increased (Fig. 3). As increasing amounts of $\mathrm{NaBH}_{4}$ were used, the production of stabilised $\mathrm{Ru}^{0}$ nanoparticles was ensured $[38,39]$. The peak in activity was observed at $\mathrm{NaBH}_{4} / \mathrm{RuCl}_{3}=2.5$, which could be due to both the required $\mathrm{Ru}$ surface species and particle sizes being achieved resulting in optimal activity. However, at higher $\mathrm{NaBH}_{4} / \mathrm{RuCl}_{3}$ ratios, the kinetics can play more of a role and resulted in increasingly large particles because of an excess amount used. Large Ru particles would have a smaller surface area than small Ru nanoparticles, which would not explain the large decrease in the catalyst surface area. It is possible that the large excess of reducing agent is changing the nature of the carbon support to become more graphitic in nature, however a significantly more detailed study would be required to confirm this. The activity data shows a decrease in activity after $\mathrm{NaBH}_{4} / \mathrm{RuCl}_{3}>2.5$. The larger particle size postulated to be caused by the increased reduction may well be the cause of this $[36,37]$.

XPS analysis of the catalysts prepared with varying amounts of $\mathrm{NaBH}_{4}$ are presented in Table 3. A Ru( $\left(3 \mathrm{~d}_{5 / 2}\right)$ peak $c a .280 \mathrm{eV}$ is found for all samples, with a further peak at $c a .281 \mathrm{eV}$ and assigned as $\mathrm{Ru}^{0}$ and $\mathrm{RuO}_{2}$ respectively. Given that less $\mathrm{gVL}$ was produced (Fig. 3) when larger amounts of $\mathrm{NaBH}_{4}$ were used during the catalyst preparation, it can be linked with the presence of an increased amount of metallic Ru on surface. The XPS data, when considered in its entirety, suggests that $\mathrm{RuO}_{2}$ must be present as the precursor to the active species under reaction conditions. Though the use of excess $\mathrm{NaBH}_{4}$ resulted in an increase in the amount of metallic $\mathrm{Ru}$, these particles were likely too large due to the high rate of reduction to be particularly active. Given that reduction of Ru in situ is likely a facile process [32] the use of smaller amounts of $\mathrm{NaBH}_{4}$ to produce smaller particles is preferable.

TPR analysis of the catalysts prepared by varying the ratio of $\mathrm{NaBH}_{4} / \mathrm{Ru}$ are presented in Fig. 5. The reduction signals were found to be comparable with those observed with the varying ratio of PVA/Ru (Fig. 2). The most notable

Table 3 XPS analysis of a selection of catalysts with different $\mathrm{NaBH}_{4} / \mathrm{RuCl}_{3}$ ratios

\begin{tabular}{llll}
\hline $\begin{array}{l}\mathrm{NaBH}_{4} / \\
\mathrm{RuCl}_{3} / \mathrm{mol} / \\
\mathrm{mol}\end{array}$ & $\mathrm{Ru}\left(3 \mathrm{~d}_{5 / 2}\right) / \mathrm{eV}$ & $\mathrm{Ru} \mathrm{species}^{\mathrm{a}}$ & Ratio $\mathrm{Ru}^{0}: \mathrm{RuO}_{2}$ \\
\hline 0.5 & 280.3 and 281.5 & $\mathrm{Ru}^{0} / \mathrm{RuO}_{2} \cdot\left(\mathrm{xH}_{2} \mathrm{O}\right)$ & $1: 6$ \\
2.5 & 280.3 and 281.3 & $\mathrm{Ru}^{0} / \mathrm{RuO}_{2} \cdot\left(\mathrm{xH}_{2} \mathrm{O}\right)$ & $1: 5$ \\
5.0 & 280.2 and 281.5 & $\mathrm{Ru}^{0} / \mathrm{RuO}_{2} \cdot\left(\mathrm{xH}_{2} \mathrm{O}\right)$ & $1: 6$ \\
7.5 & 280.2 and 281.4 & $\mathrm{Ru}^{0} / \mathrm{RuO}_{2} \cdot\left(\mathrm{xH}_{2} \mathrm{O}\right)$ & $1: 3.5$ \\
\hline
\end{tabular}

${ }^{\mathrm{a}}$ Assignments made against binding energies determined from bulk references

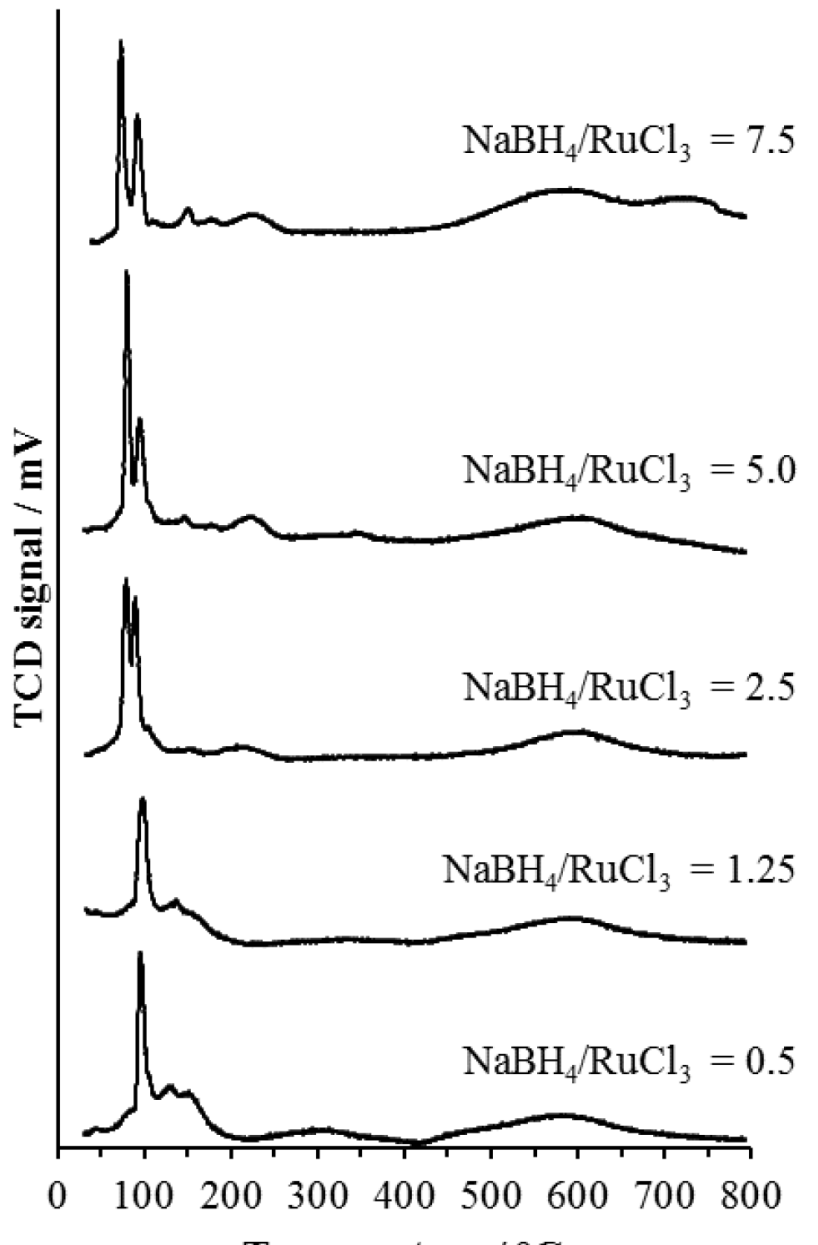

Temperature $/{ }^{\circ} \mathrm{C}$

Fig. 5 TPR profiles of the catalysts prepared by variation of $\mathrm{NaBH}_{4} /$ $\mathrm{Ru}$ ratio $(\mathrm{mol} / \mathrm{mol})$

observation from these data is the evolution of two reduction signals below $100{ }^{\circ} \mathrm{C}$ that showed a higher intensity with an increased amount of $\mathrm{NaBH}_{4}$. The catalyst prepared with 2.5 ratio of $\mathrm{NaBH}_{4}$ showed almost same intensity of both signals compared with the catalysts prepared with the higher ratios (5 and 7). The lower temperature reduction signals correspond to the facile reduction of $\mathrm{Ru}(\mathrm{OH})_{3}$, which arise due to the affinity of $\mathrm{Ru}$ with water also detected in the form of hydrated $\mathrm{RuO}_{2}$ species in XPS [33]. Each of the catalysts in this series were easily reducible under reaction conditions.

The activity of a selection of catalysts, with varying compositions of the highest and lowest PVA and $\mathrm{NaBH}_{4}$ contents, were tested at various reaction times and the data are presented in Fig. 4. The most active catalyst (PVA/ $\mathrm{Ru}=0.1 ; \mathrm{NaBH}_{4} / \mathrm{RuCl}_{3}=2.5$ ) achieved $\mathrm{gVL}$ yield of $90 \%$ after $1 \mathrm{~h}$, whereas the poorest performing catalyst (PVA/ $\mathrm{Ru}=3.0 ; \mathrm{NaBH}_{4} / \mathrm{RuCl}_{3}=2.5$ ) achieved approximately $40 \%$ yield after the same time. The catalyst prepared with an optimal content of PVA (0.1) and low $\mathrm{NaBH}_{4}(0.5)$ content was 
less active than the catalyst prepared with a large excess of $\mathrm{NaBH}_{4}$ used, in agreement with the trend previously discussed indicating that there is a minimum amount of $\mathrm{NaBH}_{4}$ required in order to fully reduce the $\mathrm{Ru}$ in solution. The key feature of all the time-on-line profiles is that there appeared to be an induction period similar to the induction period we previously reported in relation to $5 \mathrm{wt} \% \mathrm{Ru} / \mathrm{C}$ catalysts for lactic acid hydrogenation [32]. It is likely that the induction period was due to any or a combination of pre-reduction of surface $\mathrm{RuO}_{\mathrm{x}}$ to metallic $\mathrm{Ru}$ (i.e. preparation of the active surface), or due to removal of the PVA, which is known to be facile and achievable under the reaction conditions.

\subsection{Variation of Heat Treatment Temperature}

Further to this we performed a variation of heat treatment temperature on the catalyst prepared with $\mathrm{PVA} / \mathrm{Ru}=0.1$, $\mathrm{NaBH}_{4} / \mathrm{RuCl}_{3}=2.5$. All of the catalysts were tested for LA hydrogenation under identical conditions and the data are shown in Fig. 6. Interestingly all the catalysts heated after preparation shown lower activity and a steady decline in gVL yield was observed with an increase in the temperature of heat treatment. This decline in activity can be linked with the removal of PVA at the higher reaction temperature and a change in catalyst structure.

XPS analysis of the Ru after heat treatments is shown in Table 4. As evident from the $\mathrm{Ru}^{0} / \mathrm{RuO}_{2}$ ratio on heating, there is an increase in the amount of metallic $\mathrm{Ru}$, consistent with the dehydration of facilely reduced oxide species. The presence of $\mathrm{RuO}_{2}$ may be attributed to the ex situ handling of the samples prior to insertion in to the spectrometer, or dehydrated $\mathrm{RuO}_{2}$ species which are formed by annealing to $c a .300{ }^{\circ} \mathrm{C}$ [40]. TPR analysis was performed on the catalysts prepared by varying the temperature of heat treatment and their data are presented in Fig. 7. Interestingly, the

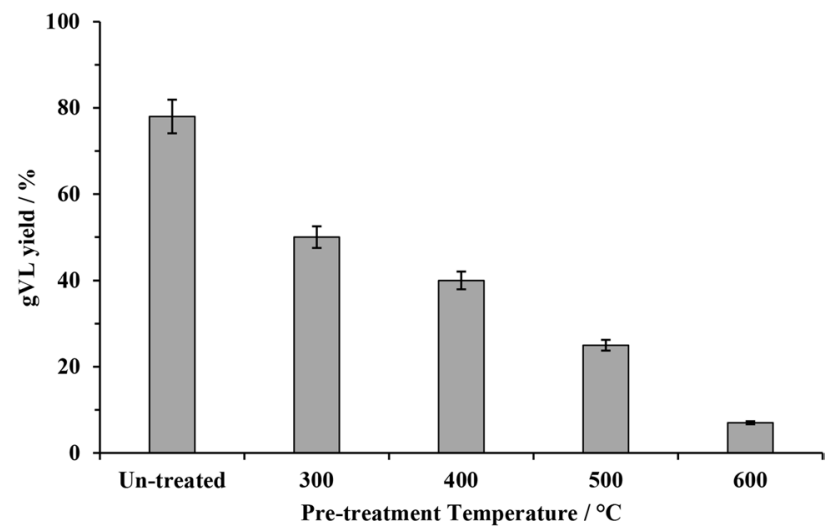

Fig. 6 Activity of $1 \mathrm{wt} \% \mathrm{Ru} / \mathrm{C}\left(\mathrm{PVA} / \mathrm{Ru}=0.1, \mathrm{NaBH}_{4} / \mathrm{RuCl}_{3}=2.5\right)$ at different heat treatment temperatures $\left(\mathrm{N}_{2}, 3 \mathrm{~h}, 10{ }^{\circ} \mathrm{C} \mathrm{min}{ }^{-1}\right)$. Reaction conditions $100{ }^{\circ} \mathrm{C}, \mathrm{H}_{2} 5 \mathrm{barg}, 1 \mathrm{~h}$, Substrate $5 \mathrm{wt} \% \mathrm{LA} / \mathrm{H}_{2} \mathrm{O}$, catalyst $(0.015 \mathrm{~g})$
Table 4 XPS analysis of a selection of catalysts with different pretreatment temperature

\begin{tabular}{lll}
\hline $\begin{array}{l}\text { Pre-treatment } \\
\text { temperature/ } /{ }^{\circ} \mathrm{C}\end{array}$ & $\mathrm{Ru}$ species & $\mathrm{Ratio} \mathrm{Ru}^{0}: \mathrm{RuO}_{2}$ \\
\hline Un-treated & $\mathrm{Ru}^{0}$ and $\mathrm{RuO}_{2}$ & $1: 5$ \\
300 & $\mathrm{Ru}^{0}$ and $\mathrm{RuO}_{2}$ & $1: 10$ \\
400 & $\mathrm{Ru}^{0}$ and $\mathrm{RuO}_{2}$ & $1: 6$ \\
600 & $\mathrm{Ru}^{0}$ and $\mathrm{RuO}_{2}$ & $1: 4$ \\
\hline
\end{tabular}

catalyst which did not go through any heat treatment after preparation (other than a drying step at $110^{\circ} \mathrm{C}$ ) showed the two reduction signals at temperatures less than $100{ }^{\circ} \mathrm{C}$ and was also the most active in terms of its catalytic activity. All of the catalysts that went through heat treatment steps after drying showed reduction at higher temperatures and the reduction signals were far less intense compared with the unheated catalyst. Based on this data we can conclude that the catalyst should have reducible Ru species for a better catalyst activity. The heat treated catalysts possessed the $\mathrm{Ru}$ species which were harder reduce under our reaction conditions.

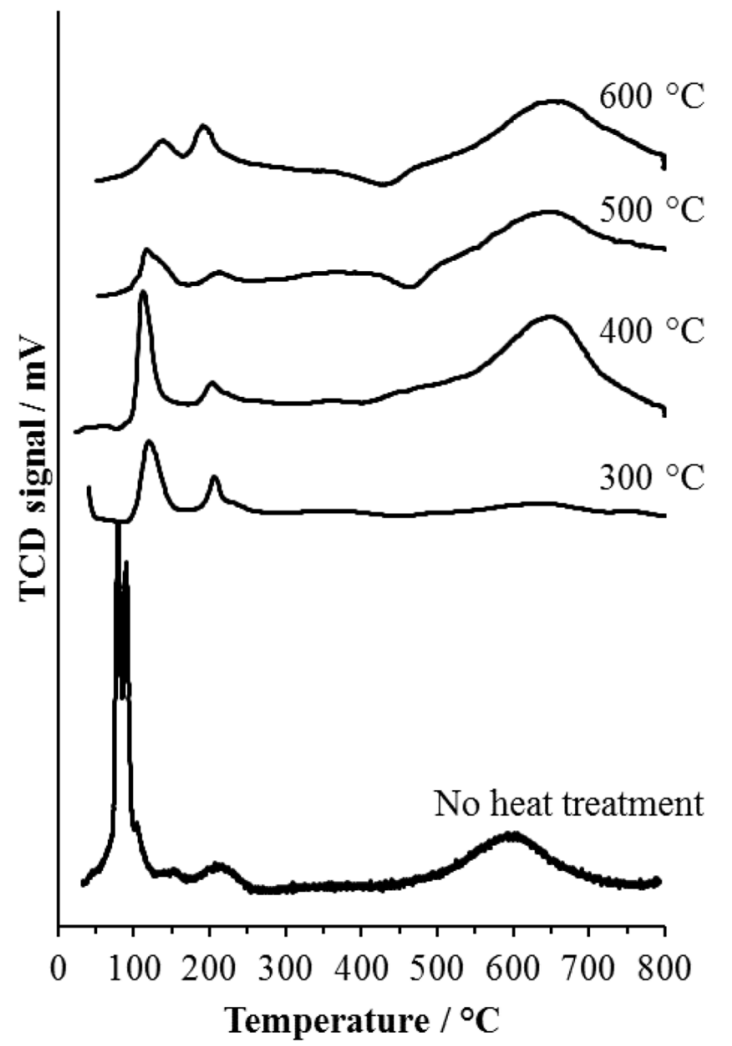

Fig. 7 TPR analysis of catalysts prepared with different heat treatment temperatures 


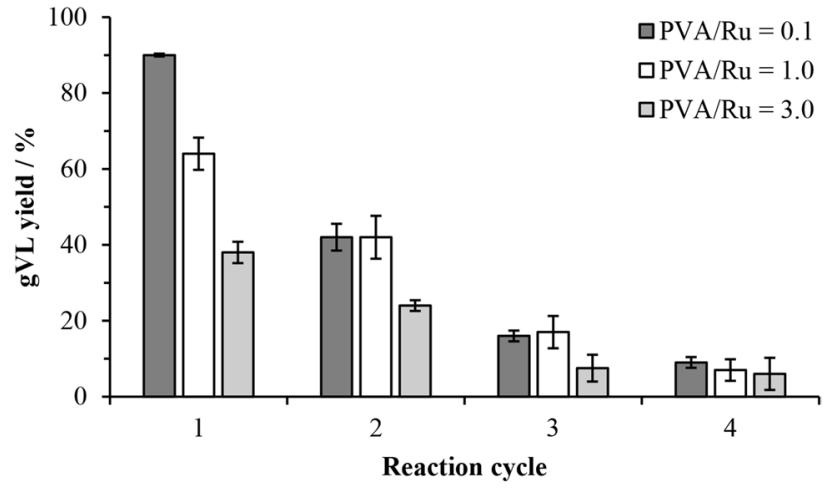

Fig. 8 Stability data for the $1 \% \mathrm{Ru} / \mathrm{C}$ catalysts prepared by the variation of $\mathrm{PVA} / \mathrm{Ru}$ ratio $(\mathrm{mol} / \mathrm{mol})$ - (no heat treatment). Reaction conditions $100{ }^{\circ} \mathrm{C}, \mathrm{H}_{2} 5 \mathrm{barg}, 1 \mathrm{~h}$, Substrate $5 \mathrm{wt} \% \mathrm{LA} / \mathrm{H}_{2} \mathrm{O}$, catalyst $(0.015 \mathrm{~g})$

Table 5 BET surface area of the most active catalyst (PVA/ $\mathrm{Ru}=0.1$ ) retrieved after reuse cycles

\begin{tabular}{ll}
\hline $\begin{array}{l}\text { Reaction } \\
\text { cycle }\end{array}$ & $\begin{array}{l}\text { BET surface area of } \\
\text { the catalyst } / \mathrm{m}^{2} \mathrm{~g}^{-1}\end{array}$ \\
\hline 1 & 200 \\
2 & 160 \\
3 & 130 \\
4 & 60 \\
\hline
\end{tabular}

Based on above data from the variation of catalyst preparation parameters we have identified that in order to have the highest activity the catalyst must have optimum $\mathrm{RuO}_{\mathrm{x}}$ species on the surface which can be reduced under reaction conditions $\left(100^{\circ} \mathrm{C}, 5\right.$ bar $\left.\mathrm{H}_{2}\right)$.

\subsection{Reusability Studies}

Reuse tests were carried out using $\mathrm{Ru} / \mathrm{C}$ catalysts prepared with $\mathrm{NaBH}_{4} / \mathrm{RuCl}_{3}=2.5$ and varying amounts of PVA. The activity data on various reuse cycles are presented in Fig. 8. After the first use, where the three catalysts showed clear differences in activity depending on the amount of PVA used, the subsequent uses showed no significant differences between them. There was a downwards trend in activity with successive reuse cycles. MP-AES analysis of the reaction solution showed no Ru leaching. It can be considered that some extent of PVA retention is responsible for the deactivation of the catalyst and an optimal amount of PVA is always required for the desired activity. On the other hand the BET data for the most effective catalyst $(\mathrm{PVA} / \mathrm{Ru}=0.1)$ presented in Table 5 showed a reasonable decline in bulk surface area, however, this decline in surface area could be due to the collapse in carbon structure over reuse. .

XPS analysis of the post-reaction sample (Fig. 9) reveals an increase in the concentration of metallic $\mathrm{Ru}$, together with the increase of surface carbon-oxygen species, which we have previously attributed to poly-lactide like species and evidenced by the increased C(1s) peaks at $c a .285$ and $289 \mathrm{eV}$ [32]. Clearly an increase in these species serves to block surface sites and supports the systematic decrease in surface area determined by BET.

Furthermore we also performed TPR analysis of the most active catalyst $(\mathrm{PVA} / \mathrm{Ru}=0.1)$ after first and the second reuse cycles and the data are presented in Fig. 10. The used catalyst showed a very broad reduction signal at $100{ }^{\circ} \mathrm{C}$ compared with the fresh catalyst which had two sharp reduction signals just below $100{ }^{\circ} \mathrm{C}$. This observation is consistent with the previous observations that the lack of reducible species is an important factor under our reaction conditions. Clearly, there are several factors linked with the loss in catalytic activity on reuse; the deposition of organic species on surface, increase in particle size and most importantly the loss of reducible $\mathrm{RuO}_{\mathrm{x}}$.

To try to identify the nature of the active catalysts we also carried out TEM analysis on the most active catalyst, the $1 \% \mathrm{Ru} / \mathrm{XC} 72 \mathrm{R}$ with PVA/metal of 0.1 and $\mathrm{NaBH}_{4} / \mathrm{RuCl}_{3}$ of 2.5. No metal particles were observed using conventional TEM, therefore we analysed the catalyst using aberration corrected TEM. It was still difficult to find metal particles on this catalyst, however, using HAADF mode some metal particles were identified, images are shown in Fig. 11. It is clear from these images that the metal particles are very small, generally around $2 \mathrm{~nm}$. This is in agreement with our previous work where we used $\mathrm{Ru} / \mathrm{XC} 72 \mathrm{R}$, however, in this previous work the total metal loading was $5 \%$ which made the metal particles easier to identify. We speculate that with the lower loading of the metal the particles in the $1 \% \mathrm{Ru}$ catalysts are smaller, however we cannot confirm this as there was insufficient particles to complete a statistically relevant particle size count. We also used aberration corrected TEM to analyse non-optimised catalysts with excess PVA and excess $\mathrm{NaBH}_{4}$ however no metal particles could be found in either case, and consistent with XPS analysis which reveals a low concentration ( $c a .0 .1$ at.\%) of $\mathrm{RuO}_{2}$ species. XPS suggests that on these catalysts the $\mathrm{RuO}_{2}$ is in a hydrated form, which is amorphous in nature and may explain why it is difficult to identify using TEM.

\section{Conclusions}

We have investigated and optimised the sol immobilization preparation method for ruthenium on carbon catalysts and tested them for the selective hydrogenation of LA into gVL. We have found that by varying the amount of PVA stabiliser, $\mathrm{NaBH}_{4}: \mathrm{Ru}$ metal and heat treatment temperature we can improve the catalytic activity. Small amounts of PVA were important to give a measure of control to the metal particle formation, the catalytic activity for LA conversion was 

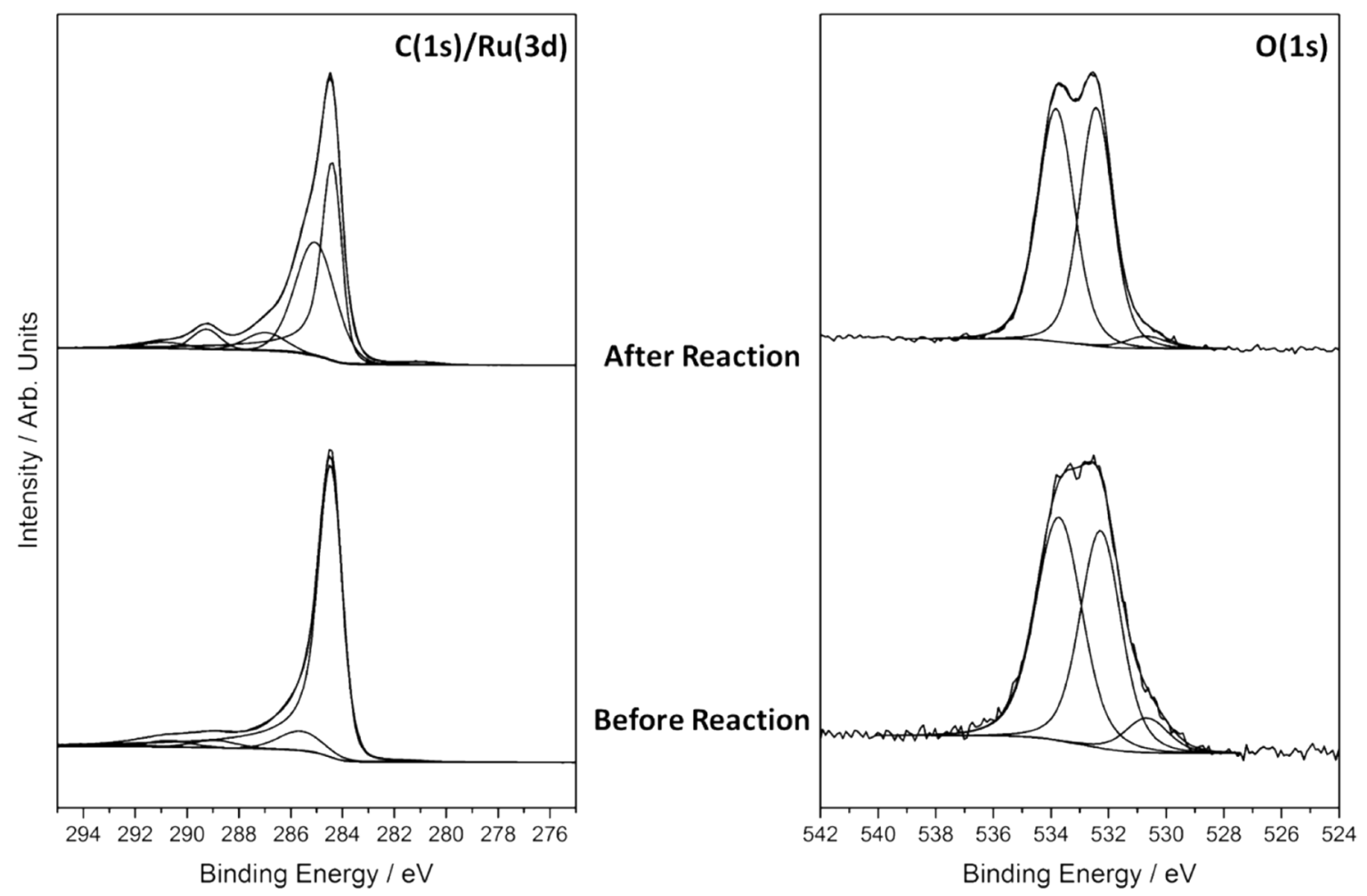

Fig. $9 \mathrm{C}(1 \mathrm{~s}) / \mathrm{Ru}(3 \mathrm{~d})$ and $\mathrm{O}(1 \mathrm{~s})$ core-levels for the catalyst $(\mathrm{PVA} / \mathrm{Ru}=0.1)$ before and after use

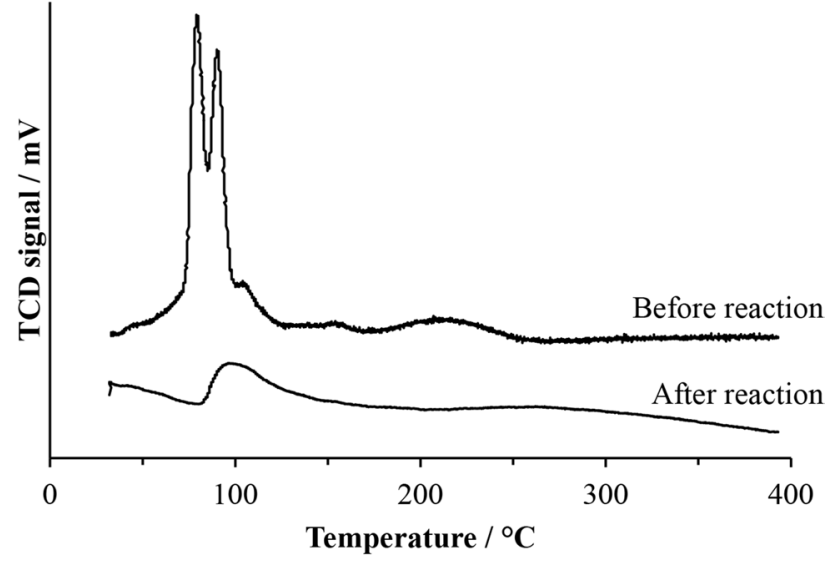

Fig. 10 TPR profile of the catalyst $(\mathrm{PVA} / \mathrm{Ru}=0.1)$ between first and second use

seen to increase vs. a catalyst prepared without using PVA. The use of an excessive PVA was detrimental to catalytic activity which we attribute to the blocking of active sites on the surface. As the use of $\mathrm{NaBH}_{4}$ during the preparation was increased, a volcano-like plot was observed for GVL yield, with $\mathrm{NaBH}_{4} / \mathrm{RuCl}_{3}=2.5$ being an optimum ratio. XPS and TPR analysis showed that even when a large excesses of $\mathrm{NaBH}_{4}$ were used, the final catalyst was comprised of mostly $\mathrm{RuO}_{2}$ on the surface. XPS analysis suggested that $\mathrm{RuO}_{2}$ (which may or may not be hydrated to some extent) is, or is the precursor to, the active Ru species during hydrogenation, as it is so ubiquitously present across the catalyst surface. The instances where $\mathrm{Ru}(\mathrm{III})$ was observed as $\mathrm{RuCl}_{3}$ correlated with poor $\mathrm{gVL}$ yields suggesting either that the presence of chloride had a poisoning effect or prevented the reduction of Ru under reaction conditions. Variation of heat treatment temperature on the catalyst had a negative effect on catalytic activity which was due to the formation of less reducible dehydrated $\mathrm{RuO}_{2}$ and metallic $\mathrm{Ru}$ on the surface of catalysts. Reuse of the catalyst showed a decline in the activity which we have attributed to the removal of PVA from the surface as well as particle sintering and growth in particle size and/or build-up of organic species on the particle surface. 
Fig. 11 HAADF images of the optimum $1 \% \mathrm{Ru} / \mathrm{XC} 72 \mathrm{R}$ catalyst $\mathrm{PVA} / \mathrm{metal}=0.1$ and $\mathrm{NaBH}_{4} / \mathrm{RuCl}_{3}=2.5$

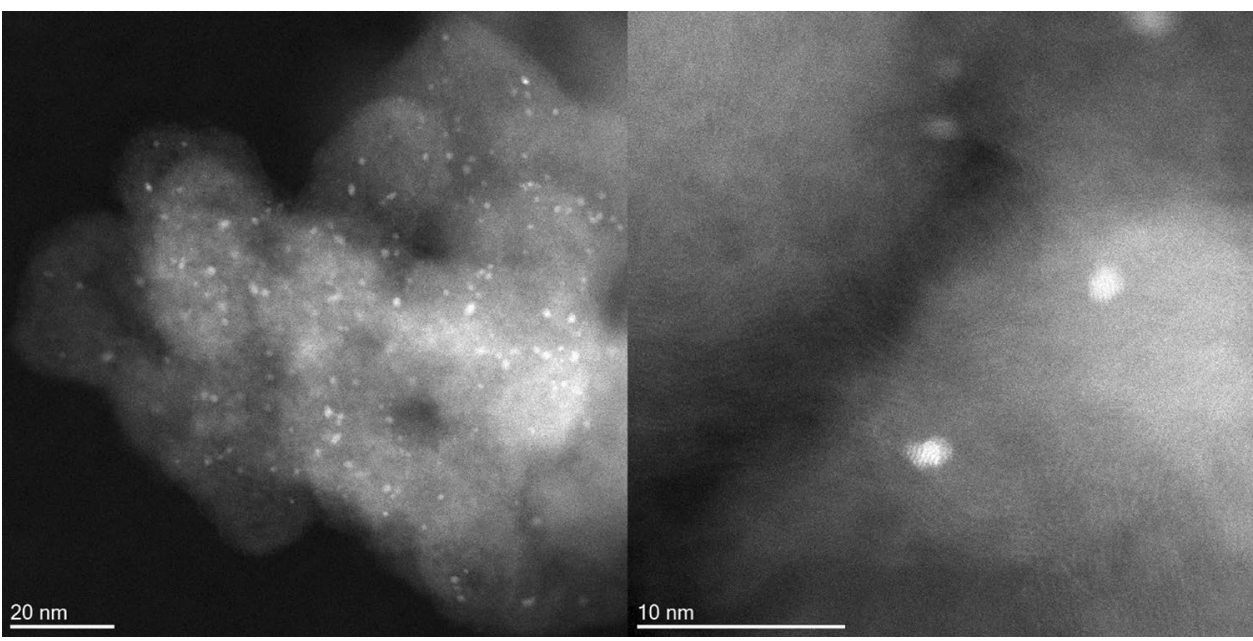

Acknowledgements This work was financially supported by the European Union FP7 NMP project NOVACAM (Novel cheap and abundant materials for catalytic biomass conversion, FP7-NMP-2013- EUJapan-604319). Dr Thomas E. Davies is gratefully acknowledged for providing with TEM images through Cardiff Microscopy Services.

Open Access This article is distributed under the terms of the Creative Commons Attribution 4.0 International License (http://creativeco mmons.org/licenses/by/4.0/), which permits unrestricted use, distribution, and reproduction in any medium, provided you give appropriate credit to the original author(s) and the source, provide a link to the Creative Commons license, and indicate if changes were made.

\section{References}

1. Zhao H, Holladay JE, Brown H, Zhang ZC (2007) Metal chlorides in ionic liquid solvents convert sugars to 5-hydroxymethylfurfural. Science 316:1597-1600

2. Corma A, Iborra S, Velty A (2007) Chemical routes for the transformation of biomass into chemicals. Chem Rev 107:2411-2502

3. Bozell J, Petersen GR (2010) Technology development for the production of biobased products from biorefinery carbohydratesthe US Department of Energy's “Top 10" revisited. Green Chem 12:539-554

4. Farone WA, Cuzens, John E (1998) Hydrolytic method for the production of levulinic acid and its derivatives from biomass and sugars. WO 9819986A1

5. Farone WA, Cuzens JE (2000) Method for the production of levulinic acid and its derivatives. US6054611A

6. Yang Y, Sun C-J, Brown DE, Zhang L, Yang F, Zhao H, Wang Y, Ma X, Zhang X, Ren Y (2016) A smart strategy to fabricate $\mathrm{Ru}$ nanoparticle inserted porous carbon nanofibers as highly efficient levulinic acid hydrogenation catalysts. Green Chem 18(12):3558-3566

7. Al-Shaal MG, Calin M, Delidovich I, Palkovits R (2016) Microwave-assisted reduction of levulinic acid with alcohols producing $\gamma$-valerolactone in the presence of a $\mathrm{Ru} / \mathrm{C}$ catalyst. Catal Commun 75:65-68

8. Cirujano FG, Corma A. Llabres i Xamena FX (2015) Conversion of levulinic acid into chemicals: synthesis of biomass derived levulinate esters over Zr-containing MOFs. Chem Eng Sci 124:52-60
9. Jones DR, Iqbal S, Ishikawa S, Reece C, Thomas LM, Miedziak PJ, Morgan DJ, Edwards JE, Bartley JK, Willock DJ, Hutchings GJ (2016) The conversion of levulinic acid into $\gamma$-valerolactone using $\mathrm{Cu}-\mathrm{ZrO}_{2}$ catalysts. Catal Sci Technol 6(15):6022-6030

10. Horvath IT, Mehdi H, Fabos V, Boda L, Mika LT (2008) $\gamma$-Valerolactone-a sustainable liquid for energy and carbon-based chemicals. Green Chem 10:238-242

11. Bond JQ, Alonso DM, Wang D, West RM, Dumesic JA (2010) Integrated catalytic conversion of $\gamma$-valerolactone to liquid alkenes for transportation fuels. Science 327:1110-1114

12. Schuette HA, Thomas RA (1930) Valerolactone. III. Preparation by the catalytic reduction of levulinic acid with hydrogen in the presence of platinum oxide. J Am Chem Soc 52:3010-3012

13. Christian RV, Brown HD, Hixon RM (1947) Derivatives of $\gamma$-valerolactone, 1,4-pentanediol, and 1,4-bis(2-cyanoethoxy) pentane. J Am Chem Soc 69:1961-1963

14. Mehdi H, Fabos V, Tuba R, Bodor A, Mika LT, Horvath IT (2008) Integration of homogeneous and heterogeneous catalytic processes for a multi-step conversion of biomass: from sucrose to levulinic acid, $\gamma$-valerolactone, 1,4-pentanediol, 2-methyl-tetrahydrofuran, and alkanes. Top Catal 48:49-54

15. Manzer LE, Hutchenson KW (2004) Catalytic intramolecular cyclocondensation production of gamma-valerolactone from levulinic acid in supercritical media. US20040254384A1,

16. Bourne RA, Stevens JG, Ke J, Poliakoff M (2007) Maximizing opportunities in supercritical chemistry: the continuous conversion of levulinic acid to $\gamma$-valerolactone in $\mathrm{CO}_{2}$. Chem Commun 44:4632-4634

17. Ortiz-Cervantes C, Garcia JJ (2013) Hydrogenation of levulinic acid to $\gamma$-valerolactone using ruthenium nanoparticles. Inorg Chim Acta 397:124-128

18. Yan ZP, Lin L, Liu S (2009) Synthesis of $\gamma$-valerolactone by hydrogenation of biomass-derived levulinic acid over $\mathrm{Ru} / \mathrm{C}$ catalyst. Energy Fuels 23:3853-3858

19. Galletti AMR, Antonetti C, De Luise V, Martinelli M (2012) A sustainable process for the production of $\gamma$-valerolactone by hydrogenation of biomass-derived levulinic acid. Green Chem 14:688-694

20. Piskun AS, de Haan JE, Wilbers E, van de Bovenkamp HH, Tang Z, Heeres HJ (2016) Hydrogenation of levulinic acid to $\gamma$-valerolactone in water using millimeter sized supported $\mathrm{Ru}$ catalysts in a packed bed reactor. ACS Sustain Chem Eng 4:2939-2950 
21. Luo W, Sankar M, Beale AM, He Q, Kiely CJ, Bruijnincx PCA, Weckhuysen BM (2015) High performing and stable supported nano-alloys for the catalytic hydrogenation of levulinic acid to $\gamma$-valerolactone. Nat Commun 6:6540

22. Wettstein SG, Bond JQ, Alonso DM, Pham HN, Datye AK, Dumesic JA (2012) RuSn bimetallic catalysts for selective hydrogenation of levulinic acid to $\gamma$-valerolactone. Appl Catal B 117-118:321-329

23. Ren W, Pan X, Wang G, Cheng W, Liu Y (2016) Dodecylated lignin-g-PLA for effective toughening of PLA. Green Chem 18(18):5008-5014

24. Deng L, Li J, Lai D-M, Fu Y, Guo Q-X (2009) catalytic conversion of biomass-derived carbohydrates into $\gamma$-valerolactone without using an external $\mathrm{H}_{2}$ supply. Angew Chem Int Ed 48:65296532, S6529/6521-S6529/6524

25. Luque R, Clark JH (2010) Water-tolerant Ru-starbon materials for the hydrogenation of organic acids in aqueous ethanol. Catal Commun 11:928-931

26. Primo A, Concepcion P, Corma A (2011) Synergy between the metal nanoparticles and the support for the hydrogenation of functionalized carboxylic acids to diols on $\mathrm{Ru} / \mathrm{TiO}_{2}$. Chem Commun 47:3613-3615

27. Xiao C, Goh T-W, Qi Z, Goes S, Brashler K, Perez C, Huang $\mathrm{W}$ (2016) Conversion of levulinic acid to $\gamma$-valerolactone over few-layer graphene-supported ruthenium catalysts. ACS Catal 6:593-599

28. Abdelrahman OA, Heyden A, Bond JQ (2014) Analysis of kinetics and reaction pathways in the aqueous-phase hydrogenation of levulinic acid to form $\gamma$-valerolactone over Ru/C. ACS Catal 4:1171-1181

29. Upare PP, Lee J-M, Hwang D-W, Halligudi SB, Hwang Y-K, Chang J-S (2011) Selective hydrogenation of levulinic acid to $\gamma$-valerolactone over carbon-supported noble metal catalysts. J Ind Eng Chem (Amst Neth) 17:287-292
30. Morgan DJ (2015) Resolving ruthenium: XPS studies of common ruthenium materials. Surf Interface Anal 47:1072-1079

31. Baltrusaitis J, Mendoza-Sanchez B, Fernandez V, Veenstra R, Dukstiene N, Roberts A, Fairley N (2015) Generalized molybdenum oxide surface chemical state XPS determination via informed amorphous sample model. Appl Surf Sci 326:151-161

32. Iqbal S, Kondrat SA, Jones DR, Schoenmakers DS, Edwards JE, Lu L, Yeo BR, Wells PP, Gibson EK, Morgan DJ, Kiely CJ, Hutchings GJ (2015) Ruthenium nanoparticles supported on carbon: an active catalyst for the hydrogenation of lactic acid to 1,2-propanediol. ACS Catal 5:5047-5059

33. Rossetti I, Pernicone N, Forni L (2003) Characterization of Ru/C catalysts for ammonia synthesis by oxygen chemisorption. Appl Catal A 248:97-103

34. Hengne AM, Biradar NS, Rode CV (2012) Surface species of supported ruthenium catalysts in selective hydrogenation of levulinic esters for bio-refinery application. Catal Lett 142:779-787

35. Turkevich J (1985) Colloidal gold. Part I. Historical and preparative aspects, morphology and structure. Gold Bull 18:86-91

36. Prati L, Martra G (1999) New gold catalysts for liquid phase oxidation. Gold Bull (London) 32:96-101

37. Prati L, Villa A (2012) The art of manufacturing gold catalysts. Catalysts 2:24-37

38. Patharkar RG, Nandanwar SU, Chakraborty M (2013) Synthesis of colloidal ruthenium nanocatalyst by chemical reduction method. J Chem. https://doi.org/10.1155/2013/831694

39. Zahmakiran M, Oezkar S (2006) Water dispersible acetate stabilized ruthenium $(0)$ nanoclusters as catalyst for hydrogen generation from the hydrolysis of sodium borohyride. J Mol Catal A 258:95-103

40. Foelske A, Barbieri O, Hahn M, Kotz R (2006) An X-ray photoelectron spectroscopy study of hydrous ruthenium oxide powders with various water contents for supercapacitors. Electrochem Solid-State Lett 9:A268-A272 